\title{
Angiotensin Receptor Blockers Are Associated with Reduced Fibrosis and Interleukin-6 Expression in Calcific Aortic Valve Disease
}

\author{
Nancy Côtéa Ablajan Mahmut ${ }^{a}$ Dominique Fournier ${ }^{a} \quad$ Marie-Chloé Boulanger ${ }^{a}$ \\ Christian Couture $^{b}$ Jean-Pierre Després ${ }^{b}$ Sylvain Trahan ${ }^{b}$ Yohan Bossé $^{b}$ \\ Sylvain Pagéb Philippe Pibarot $^{b}$ Patrick Mathieu ${ }^{a}$ \\ a Laboratoire d'Études Moléculaires des Valvulopathies, Groupe de Recherche en Valvulopathies, Quebec Heart and \\ Lung Institute Research Center, Department of Surgery and ${ }^{\mathrm{b}}$ Institut Universitaire de Cardiologie et de Pneumologie \\ de Québec, Laval University, Quebec, Que., Canada
}

\section{Key Words}

Calcific aortic valve disease $\cdot$ Aortic stenosis - Angiotensin receptor blockers - Small dense low-density lipoproteins .

Fibrosis · Inflammation · Interleukin-6

\begin{abstract}
Background: Calcific aortic valve disease (CAVD) is a chronic disorder characterized by the mineralization of the aortic valve and involving fibrosis. Objectives: In this work we sought to determine if the fibrotic component of the remodeling process of CAVD was related to the use of angiotensin-converting enzyme inhibitors (ACEi) and/or angiotensin receptor blockers (ARBs). Methods: In 477 patients with CAVD, the aortic valve was examined by histology. A semiquantitative score of fibrosis was generated and associations with clinical/cardiometabolic variables examined. In a subset of 103 patients the aortic valve was available to study the infiltration by inflammatory cells and expression of interleukin-6 (IL-6) by quantitative real-time PCR. Results: The fibrosis score of the aortic valve was independently related to the hemodynamic severity of CAVD measured by echocardiography. The fibrotic score of the aortic valve was also related to the expression of IL- 6 . The use of ARBs but not of ACEi was associated with a lower
\end{abstract}

fibrosis score of the aortic valve even after correction for covariates. In addition, patients under ARBs had lower aortic valve inflammation and expression of IL-6. Conclusions: These findings suggest that ARBs may alter the fibrotic process of the aortic valve in CAVD, possibly by lowering tissue inflammation.

Copyright ๑ 2013 S. Karger AG, Basel

\section{Introduction}

Calcific aortic valve disease (CAVD) is the most frequent heart valve disorder. To date there is no medical treatment for CAVD [1]. Clinical risk factors such as age, male gender, diabetes, hypertension and features of the metabolic syndrome have been associated with CAVD [2]. Over the past decade, the prevalence of CAVD has increased and it is believed that aging of the population as well as the epidemic of obesity may have contributed to this phenomenon [3]. In this regard, obesity is associated with a plethora of metabolic dysfunction, including the production of small, dense low-density lipoproteins (LDL) and activation of the renin angiotensin system (RAS), which promotes inflammation and the development of cardiovascular disorders $[4,5]$. 
CAVD is an inflammatory disorder characterized by the progressive fibrosis and mineralization of aortic tissue [6]. However, the fibrotic component and its relative contribution to the pathobiology of CAVD are still illdefined. Studies have highlighted that several components of the RAS including angiotensin-converting enzyme (ACE) and chymase, two enzymes that generate angiotensin II, are present within CAVD valves $[7,8]$. Hence, inhibition of the RAS either with ACE inhibitors (ACEi) or angiotensin receptor blockers (ARBs) may help reduce fibrosis of the aortic valve during CAVD.

Studies indicate that angiotensin II promotes inflammation and fibrosis. On the other hand, interleukin-6 (IL-6) is a pleiotropic cytokine secreted by macrophages and fibroblasts, which is liberated in response to angiotensin II [9]. Recent investigations indicate that angiotensin II-induced IL-6 expression is a key factor involved in fibrotic response [10]. Hence, the objectives of the present work were the following: (1) to examine the association between the fibrotic process and the severity of CAVD, (2) to document the relationships between the fibrotic process, inflammation and IL-6 and (3) to explore the relationships between the ARBs, ACEi with inflammation and the fibrotic remodeling of the aortic valve.

\section{Materials and Methods}

\section{Patients}

We examined 477 aortic valves that were explanted from patients at the time of aortic valve replacement for CAVD. The protocol was approved by the local ethical committee and informed consent was obtained from the subjects. Demographic data and medications of the patients (including ARBs and ACEi) were recorded. There was no patient under double therapy (ARBs and ACEi). Duration of treatment with ARBs and ACEi was not available. Patients with history of rheumatic disease, endocarditis and inflammatory diseases were excluded. Valves with an aortic valve regurgitation grade $>2+$ were excluded. Patients with reduced left ventricular ejection fraction $<40 \%$ were excluded. All patients underwent a comprehensive Doppler echocardiographic examination preoperatively. Doppler echocardiographic measurements included the left ventricular stroke volume and transvalvular gradients using the modified Bernoulli equation.

\section{Valve Histology and Weight of Aortic Valve}

Each valve excised at the time of surgery was placed in a container filled with HEPES solution and analyzed at the pathology department. As part of an ongoing protocol, one cusp was also placed in RNAlater (Ambion Inc., Austin, Tex., USA) for ulterior use. The amount of RNAlater was identical for every specimen and of known weight, thus allowing the precise determination of aortic cusp weight. The cusps in HEPES solution were removed from the container, placed on absorbent paper and then weighed on a laboratory scale. The weight of the valve was then determined by the sum of weighed cusps in HEPES and in RNAlater. Then, one cusp was snap frozen in liquid nitrogen for ulterior quantification of calcium content (103 valves were available for quantification of calcium content). The remaining cusps were decalcified in Cal-Ex (Fisher Scientific, Nepean, Ont., Canada) for $24 \mathrm{~h}$ and fixed in formaldehyde $10 \%$ for histological processing; $5-\mu \mathrm{m}$ thick sections were obtained and stained with hematoxylin eosin. Histological sections were analyzed and the degree of valvular tissue fibrosis was attributed by a visual semiquantitative score as follows: score 1 = fibrotic tissue representing less than $25 \%$ of the section surface; score 2 = fibrotic tissue representing a surface between 25 and $50 \%$ of the section surface; score $3=$ fibrotic tissue representing more than $50 \%$ of the aortic surface. The fibrosis score was attributed by experienced cardiovascular pathologists (C.C., S.P. and S.T.) blinded to clinical and echocardiographic data. The fibrotic score was validated in 25 valves by picrosirius staining for collagen. The 5 - $\mu \mathrm{m}$-thick cusp sections were stained with $0.1 \%$ sirius red in saturated picric acid (Spectrum Chemical, Gardena, N.B., Canada) and observed under polarized light microscopy. The quantitative morphometric analysis of collagen fiber was evaluated in the following manner: using a microscope at $10 \times$ magnification, the total area of each valve was determined with Image-Pro Plus version 6.1 image analysis software. Using a $40 \times$ magnification, the quantity of collagen, represented by red pixels in polarized light, was measured on the entire valve section. Then, the percentage of collagen pixels on the total area of the valves was calculated and the results were expressed as pixels $/ \mathrm{mm}^{2}$ of tissue.

\section{Immunohistochemical Analysis and Quantitative}

\section{Determination of Valve Inflammation}

Immunohistology was performed in cryostat sections of 103 valves available for further analyses. Immunohistological analysis was performed using the mouse Mab anti-monocyte/macrophages CD68+ (Cedarlane, Hornby, Ont., Canada). Slides were then incubated with an anti-mouse EnVision Dual Link SystemHRP, followed by AEC substrate (Dako, Carpinteria, Calif., USA). Tissue sections were counterstained with hematoxylin (Dako). Mouse serum was used as a negative control in immunohistological experiments. In order to assess the numbers of monocytes/ macrophages $(\mathrm{CD} 68+)$ representative regions rich in cells were detected in each section and the number of cells was counted by two observers blinded to clinical results. The cells were counted at $400 \times$ in triplicates, and a mean value was attributed to each valve. Data were reported as the average number of cells per $400 \times$ field.

\section{RNA Extraction and Real-Time PCR}

In 103 CAVD valves, RNA was extracted. Total RNA was isolated with the RNeasy micro kit (Qiagen, Mississauga, Ont., Canada). The RNA extraction protocol was performed according to the manufacturer's instructions using $100 \mathrm{mg}$ of tissue. The quality of total RNA was monitored by capillary electrophoresis (Experion, Bio-Rad, Mississauga, Ont., Canada); $1 \mu \mathrm{g}$ of RNA was reverse transcribed using the QuantiTect Reverse Transcription Kit from Qiagen. Quantitative real-time PCR (qPCR) was performed with QuantiTect SYBR Green PCR kit from Qiagen in the Rotor-Gene 6000 system (Corbett Robotics Inc., San Francisco, Calif., USA). IL-6, MCP-1, TNF- $\alpha$ and IL-1 $\beta$ (Qiagen) were quantified with real-time $\mathrm{qPCR}$ under the following conditions: an ini- 

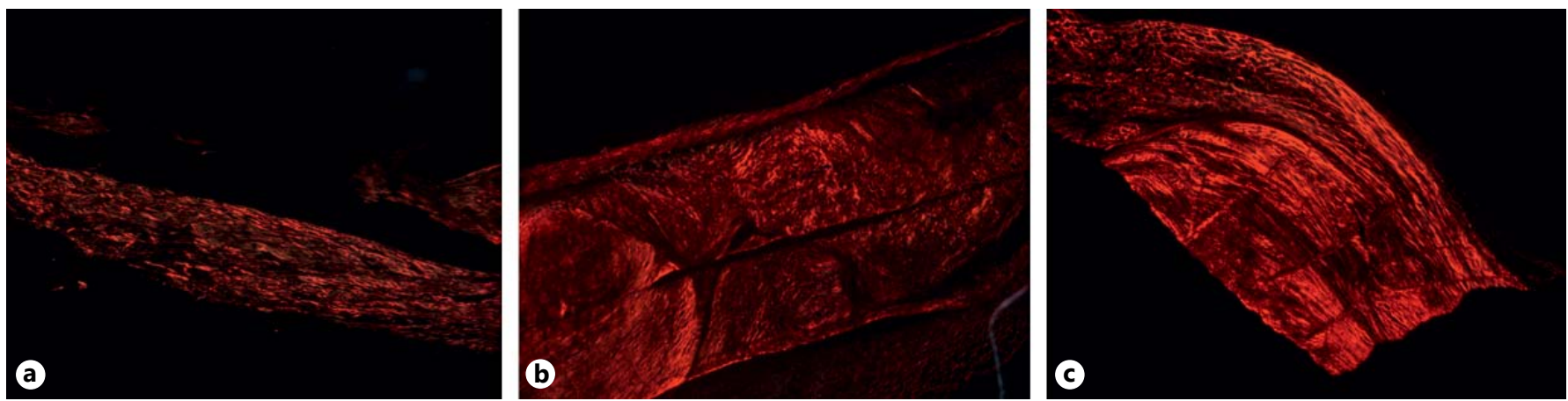

Fig. 1. Polarized light microscopy of picrosirius red staining in CAVD from patients with fibrosis score 1 (a), fibrosis score 2 (b) and fibrosis score 3 (c). We documented the presence of characteristic red polarized light in CAVD valves $(\mathbf{a}-\mathbf{c})$ indicating the presence of collagen fibers $(40 \times)$. d A positive association between the visual semiquantitative fibrosis score and the quantitative morphometric analyses of collagen was found. ${ }^{*} \mathrm{p}<0.05$ compared to fibrosis score $1 ;{ }^{\#} \mathrm{p}<0.05$ compared to fibrosis score 2 .

tial 15 -min run at $95^{\circ} \mathrm{C}$ before starting, then $94^{\circ} \mathrm{C}$ for $10 \mathrm{~s}, 55^{\circ} \mathrm{C}$ for $30 \mathrm{~s}$ and $72^{\circ} \mathrm{C}$ for $30 \mathrm{~s}$ for a total of 40 cycles. The expression of a reference gene, HPRT (Invitrogen, Burlington, Ont., Canada; coding: TGG CGT CGT GAT TAG TGA TG, non-coding: AAT CCA GCA GGT CAG CAA AG), was chosen as a normalizer to control for any difference in the amount of cDNA starting material. The real-time PCR for HPRT was done under the following conditions: an initial $15 \mathrm{~min}$ run at $95^{\circ} \mathrm{C}$ before starting, then $94^{\circ} \mathrm{C}$ for $10 \mathrm{~s}, 58^{\circ} \mathrm{C}$ for $30 \mathrm{~s}$ and $72^{\circ} \mathrm{C}$ for $30 \mathrm{~s}$ for a total of 40 cycles.

\section{Determination of Valvular Calcium Concentration}

In 103 patients additional tissues were available from the ongoing protocol to measure calcium. In these patients, a segment of valve tissue was kept in liquid nitrogen until determination of the calcium content. Leaflets were homogenized and treated with $\mathrm{HCl} 6 \mathrm{~N}$ at $95^{\circ} \mathrm{C}$ for $24 \mathrm{~h}$. The treated tissues were then centrifuged at 4,400 RPM for $30 \mathrm{~min}$ and supernatants were collected. Calcium content was determined by the Arsenazo III method. Results were expressed as milligrams of calcium per wet weight of tissue (mg/g ww).

\section{Lipid and Metabolic Profile}

Overnight fasting plasma was collected and immediately processed by the laboratory for the measurement of total cholesterol, LDL, high-density lipoprotein cholesterol (HDL) and triglycerides. The size of LDL particles was determined on a polyacrylamide gradient gel electrophoresis as previously detailed [11].

Statistical Analysis

Continuous data were expressed as mean \pm SEM and compared using Student's t test (when 2 groups were compared) or one-way ANOVA to test the effect of group (when more than 2 groups were compared). Post hoc Tukey analyses were done when the $\mathrm{p}$ value of the ANOVA was $<0.05$. Categorical data were expressed as a percentage and compared with the $\chi^{2}$ test. Correlations between variables were determined using Spearman's coefficients. Multiple linear regression analysis was used to identify the independent correlates. Variables with a $p$ value $<0.1$ were considered for entering into the multiple linear regression analysis. A $p$ value $<0.05$ was considered significant. Statistical analysis was performed with a commercially available software package, JMP 8.0.1.

\section{Results}

Fibrosis of the Aortic Valve and its Relationship with the Hemodynamic Severity of Aortic Stenosis

The semiquantitative fibrosis score of the aortic valve was first corroborated in a subset of 25 aortic valves in which quantitative morphometric analysis of fibrosis was documented after picrosirius red staining. The amount of collagen within the aortic valves increased significantly with the fibrosis score $(\mathrm{p}<0.0001$, ANOVA; fig. 1$)$. In turn, 


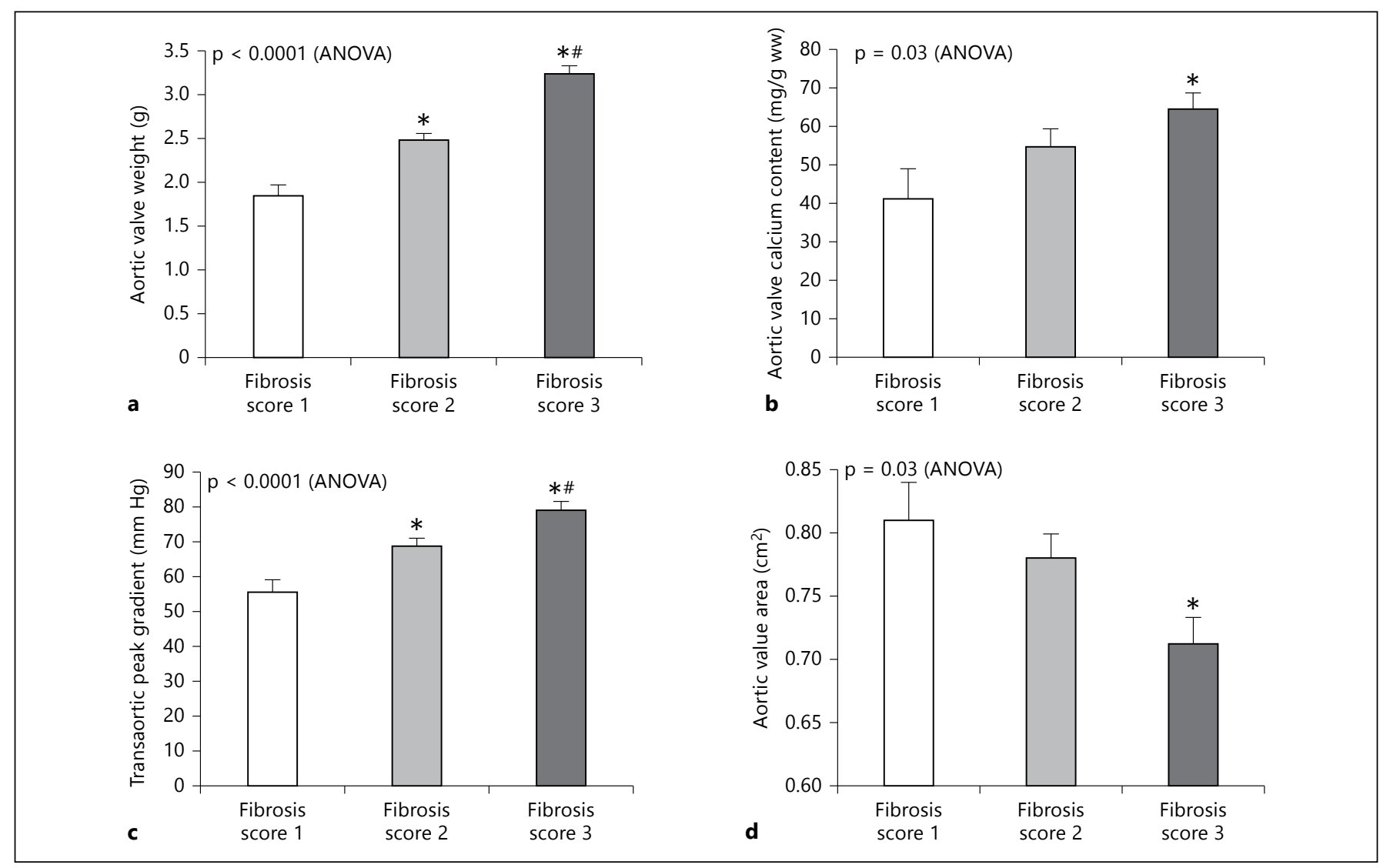

Fig. 2. a Positive relationship between fibrosis score and aortic valve weight. b Aortic valve calcium content in relation to fibrosis score. Transvalvular peak gradient was positively associated with

Table 1. Multivariate linear analysis of transaortic peak gradient

\begin{tabular}{lcc}
\hline Variables & $\beta$ coefficient & p value \\
\hline Age & 0.04 & 0.9 \\
Male gender & -5.75 & 0.003 \\
BAV & 0.03 & 0.9 \\
Fibrosis score & 6.95 & 0.02 \\
Aortic valve weight & 12.02 & $<0.0001$ \\
\hline
\end{tabular}

$\mathrm{r}^{2}$ adjusted $=0.25 ; \mathrm{p}<0.0001$.

the fibrosis score was associated with an elevated aortic valve weight, a marker of remodeling related to the severity of CAVD (fig. 2a). The fibrosis score was also significantly related to the amount of calcium within the aortic valve, indicating that both mineralization and fibrotic processes are closely associated during the development of CAVD (fig. 2b). In addition, the fibrosis score of the aortic the valve fibrosis score (c), whereas the fibrosis score was inversely related to the aortic valve area $(\mathbf{d}) .{ }^{*} \mathrm{p}<0.05$ compared to fibrosis score $1 ;{ }^{\#} \mathrm{p}<0.05$ compared to fibrosis score 2 . valve was associated with a higher peak transvalvular gradient and lower aortic valve area (fig. 2c, d). After correction for covariates including age, male gender and bicuspid aortic valve (BAV), the fibrosis score $(\beta=6.95, p=0.02)$ and weight of the aortic valve $(\beta=12.02, \mathrm{p}<0.0001) \mathrm{rem}$ ained independently associated with the transaortic peak gradient, a measure of hemodynamic severity of CAVD $\left(\mathrm{r}^{2}\right.$ adjusted $=0.25, \mathrm{p}<0.0001$; table 1$)$. In the multivariate model, when replacing the weight of the aortic valve with the valvular calcium concentration, the fibrosis score $(\beta=$ 9.6, $\mathrm{p}=0.001$ ) remained independently related to the transaortic peak gradient $\left(\mathrm{r}^{2}\right.$ adjusted $\left.=0.14, \mathrm{p}=0.0002\right)$.

\section{The Size of LDL Particles Is Inversely Related to the Fibrotic Process of CAVD Valves}

Table 2 shows the characteristics of the 477 patients with CAVD according to the fibrosis score. There were 98 patients $(20 \%)$ with a fibrosis score of 1 , whereas there were $219(46 \%)$ and $160(34 \%)$ subjects with a score of 2 and 3 , 
Table 2. Characteristics at the time of the surgery of patients in different fibrosis score groups

\begin{tabular}{|c|c|c|c|c|}
\hline Variables & $\begin{array}{l}\text { Fibrosis score } 1 \\
(\mathrm{n}=98 ; 20 \%)\end{array}$ & $\begin{array}{l}\text { Fibrosis score } 2 \\
(\mathrm{n}=219 ; 46 \%)\end{array}$ & $\begin{array}{l}\text { Fibrosis score } 3 \\
(\mathrm{n}=160 ; 34 \%)\end{array}$ & $\mathrm{p}$ value \\
\hline \multicolumn{5}{|l|}{ Clinical } \\
\hline Male gender, $\%$ & 50 & 67.3 & 72.8 & 0.0007 \\
\hline BMI, $\mathrm{kg} / \mathrm{m}^{-2}$ & $28.1 \pm 4.4$ & $29.1 \pm 5.3$ & $29.8 \pm 5.8$ & NS \\
\hline $\mathrm{BAV}, \%$ & 19.4 & 22.8 & 48.8 & $<0.0001$ \\
\hline Systolic blood pressure, $\mathrm{mm} \mathrm{Hg}$ & $133 \pm 17$ & $130 \pm 18$ & $130 \pm 20$ & NS \\
\hline Diastolic blood pressure, $\mathrm{mm} \mathrm{Hg}$ & $72 \pm 9.2$ & $73 \pm 10$ & $74 \pm 10$ & NS \\
\hline Mean blood pressure, $\mathrm{mm} \mathrm{Hg}$ & $92 \pm 10$ & $92 \pm 11$ & $93 \pm 12$ & NS \\
\hline Ejection fraction, $\%$ & $62.4 \pm 1.4$ & $62 \pm 0.9$ & $63.4 \pm 0.9$ & NS \\
\hline Coronary artery disease, $\%$ & 57.1 & 48.8 & 33.3 & 0.003 \\
\hline ACEi, \% & 41.5 & 45.8 & 54.7 & NS \\
\hline ARBs, \% & 30.8 & 22.3 & 14.3 & 0.03 \\
\hline Statin, \% & 96.4 & 95.9 & 95.2 & NS \\
\hline \multicolumn{5}{|l|}{ Laboratory data } \\
\hline LDL cholesterol, mmol/l & $2.09 \pm 0.77$ & $2.11 \pm 0.84$ & $2.32 \pm 0.82$ & 0.03 \\
\hline LDL particle size, $\AA$ & $259.9 \pm 6.2$ & $258.9 \pm 5.1$ & $256.8 \pm 5.1$ & 0.03 \\
\hline Apolipoprotein B, g/l & $0.74 \pm 0.29$ & $0.67 \pm 0.23$ & $0.67 \pm 0.2$ & NS \\
\hline HDL cholesterol, mmol/l & $1.3 \pm 0.41$ & $1.28 \pm 0.34$ & $1.27 \pm 0.36$ & NS \\
\hline Triglycerides, mmol/l & $1.46 \pm 0.76$ & $1.49 \pm 0.82$ & $1.57 \pm 0.89$ & NS \\
\hline Creatinine, $\mu \mathrm{mol} / \mathrm{l}$ & $86 \pm 26$ & $88 \pm 21$ & $92 \pm 34$ & NS \\
\hline
\end{tabular}

Values are expressed as mean $\pm \mathrm{SD}$.

respectively. There was a higher proportion of male patients and smokers in the groups with higher valve fibrosis scores. In addition, patients with an elevated fibrosis score were younger and had a lower prevalence of diabetes, hypertension and coronary artery disease. There were more BAV among patients with a higher fibrosis score. Among variables of the blood lipid profile, patients with a higher fibrosis score had higher LDL plasma levels and smaller LDL particle size. The proportions of patients under statin treatment were similar among the different fibrosis score groups. After correction for covariates including age, smoking, diabetes, LDL plasma level, male gender and BAV, the size of LDL particles $(\beta=-0.02, p=0.03)$ remained inversely associated with the fibrosis score of the aortic valve $\left(\mathrm{r}^{2}\right.$ adjusted $=0.20, p<0.0001$; table 3 ). It is relevant to point out that after multivariate adjustments, LDL plasma level $(\beta=$ $0.02, \mathrm{p}=0.7)$ was no longer associated with the fibrosis score. Patients with or without statin treatment had a similar size of LDL particles $(257.7 \pm 0.5$ vs. $257.8 \pm 4.4 \AA$, $\mathrm{p}=0.5)$.
Table 3. Multivariate linear analysis of fibrosis score

\begin{tabular}{lcl}
\hline Variables & $\beta$ coefficient & p value \\
\hline Age & -0.01 & 0.2 \\
Male gender & 0.18 & 0.01 \\
Smoking status & 0.13 & 0.2 \\
BAV & 0.19 & 0.01 \\
Diabetes & -0.08 & 0.27 \\
LDL plasma level & 0.02 & 0.7 \\
LDL particle size & -0.02 & 0.03 \\
\hline
\end{tabular}

$\mathrm{r}^{2}$ adjusted $=0.20 ; \mathrm{p}<0.0001$.

\section{ARBs Are Independently Related to Lower Fibrosis} Score of CAVD Valves

According to the fibrosis score, less patients were treated with ARBs in valves with higher grades of fibrosis (grade $1=30.8 \%$, grade $2=22.0 \%$ and grade $3=14.3 \%$, 
Table 4. Characteristics at the time of the surgery of patients with our without ARB therapy

\begin{tabular}{|c|c|c|c|c|}
\hline Variables & $\begin{array}{l}\text { ARBs } \\
(\mathrm{n}=102 ; 21 \%)\end{array}$ & $\begin{array}{l}\text { ACEi } \\
(\mathrm{n}=226 ; 47 \%)\end{array}$ & $\begin{array}{l}\text { No } \\
(\mathrm{n}=149 ; 32 \%)\end{array}$ & $\mathrm{p}$ value \\
\hline \multicolumn{5}{|l|}{ Clinical } \\
\hline Age, years & $71 \pm 8$ & $70 \pm 8$ & $70 \pm 11$ & NS \\
\hline Male gender, $\%$ & 54.9 & 73.1 & 64.6 & NS \\
\hline BMI, $\mathrm{kg} / \mathrm{m}^{2}$ & $30.4 \pm 5.4$ & $29.3 \pm 5.4$ & $27.9 \pm 5.2$ & 0.0003 \\
\hline $\mathrm{BAV}, \%$ & 24.5 & 30.6 & 35.4 & NS \\
\hline Systolic blood pressure, $\mathrm{mm} \mathrm{Hg}$ & $132 \pm 18$ & $130 \pm 18$ & $130 \pm 18$ & NS \\
\hline Diastolic blood pressure, $\mathrm{mm} \mathrm{Hg}$ & $73 \pm 10$ & $73 \pm 11$ & $73 \pm 10$ & NS \\
\hline Ejection fraction, $\%$ & $64.3 \pm 9.1$ & $61.1 \pm 9.9$ & $62.7 \pm 9.3$ & NS \\
\hline Coronary artery disease, $\%$ & 43.1 & 51.3 & 40.2 & NS \\
\hline Diabetes, \% & 33.3 & 42.9 & 21.7 & $<0.0001$ \\
\hline \multicolumn{5}{|l|}{ Medication } \\
\hline Statin, $\%$ & 95.5 & 96 & 95.4 & NS \\
\hline \multicolumn{5}{|l|}{ Laboratory data } \\
\hline LDL cholesterol, mmol/l & $2.03 \pm 0.73$ & $1.96 \pm 0.7$ & $2.36 \pm 0.88$ & $<0.0001$ \\
\hline LDL particle size, $\AA$ & $255.4 \pm 4$ & $259.4 \pm 5.3$ & $257.9 \pm 5.5$ & 0.04 \\
\hline Apolipoprotein B, g/l & $0.72 \pm 0.19$ & $0.61 \pm 0.2$ & $0.73 \pm 0.23$ & 0.04 \\
\hline HDL cholesterol, $\mathrm{mmol} / \mathrm{l}$ & $1.26 \pm 0.36$ & $1.23 \pm 0.35$ & $1.32 \pm 0.37$ & 0.04 \\
\hline Triglycerides, mmol/l & $1.65 \pm 1$ & $1.52 \pm 0.8$ & $1.43 \pm 0.74$ & NS \\
\hline Creatinine, $\mu \mathrm{mol} / 1$ & $86.7 \pm 19$ & $95.6 \pm 27$ & $84.6 \pm 21$ & 0.02 \\
\hline Aortic valve calcium content, mg/g & $48.5 \pm 7.5$ & $59.7 \pm 5.6$ & $55.1 \pm 4.1$ & NS \\
\hline Aortic valve weight, $g$ & $2.42 \pm 1.1$ & $2.59 \pm 1.2$ & $2.7 \pm 1.1$ & 0.05 \\
\hline \multicolumn{5}{|l|}{ Doppler echocardiographic data } \\
\hline
\end{tabular}

Values are expressed as mean $\pm \mathrm{SD}$.

$\mathrm{p}=0.03$, ANOVA; fig. 3). Of note, the proportion of patients under ACEi in different fibrosis score groups was not significantly different (fig. 3). Patients treated with ARBs or ACEi had a similar amount of calcium within CAVD valves $(48.5 \pm 7.5$ vs. $59.7 \pm 5.6 \mathrm{mg} / \mathrm{g} \mathrm{ww})$ as those without medication, i.e. no ARBs or ACEi (55.1 \pm $4.1 \mathrm{mg} / \mathrm{g} w \mathrm{w}, \mathrm{p}=0.4$, ANOVA), suggesting that potentially the effect of this class of medication on the remodeling process is mainly through the fibrotic process. It should be highlighted that patients with ARB treatment had smaller LDL particle size compared to patients without this medication $(\mathrm{ARBs}=255.4 \pm 4, \mathrm{ACEi}=259.4 \pm 5.3$ and no medication $=257.91 \pm 5.5 \AA, p=0.04$; table 4$)$. Despite the fact that patients under ARB treatment had higher BMI, waist circumference, prevalence of hypertension and lower LDL particle size, the use of ARBs $(\beta=-0.34, p=0.003)$ re- mained independently and inversely associated with the fibrosis score of the aortic valve even after corrections for the following covariates: age, male gender, BMI, mean blood pressure, $\mathrm{BAV}$, aortic valve weight, and the size of LDL particles $\left(\mathrm{r}^{2}\right.$ adjusted $=0.67, \mathrm{p}<0.0001$; table 5$)$. Even when forcing the peak transaortic gradient in the multivariate model, the use of ARBs $(\beta=-0.45, \mathrm{p}=0.005) \mathrm{re}$ mained independently and inversely related to the fibrotic score $\left(\mathrm{r}^{2}\right.$ adjusted $\left.=0.67, \mathrm{p}<0.0001\right)$. Also, considering that the group under ACEi had a slightly elevated proportion of diabetic patients and higher creatinine value, we introduced in a third model, diabetes and creatinine values, to the aforementioned variables. In this model, the use of ARBs $(\beta=-0.41, p=0.0002)$ remained independently and inversely related to the fibrosis score $\left(\mathrm{r}^{2}\right.$ adjusted $=$ $0.59, \mathrm{p}<0.0001)$. 


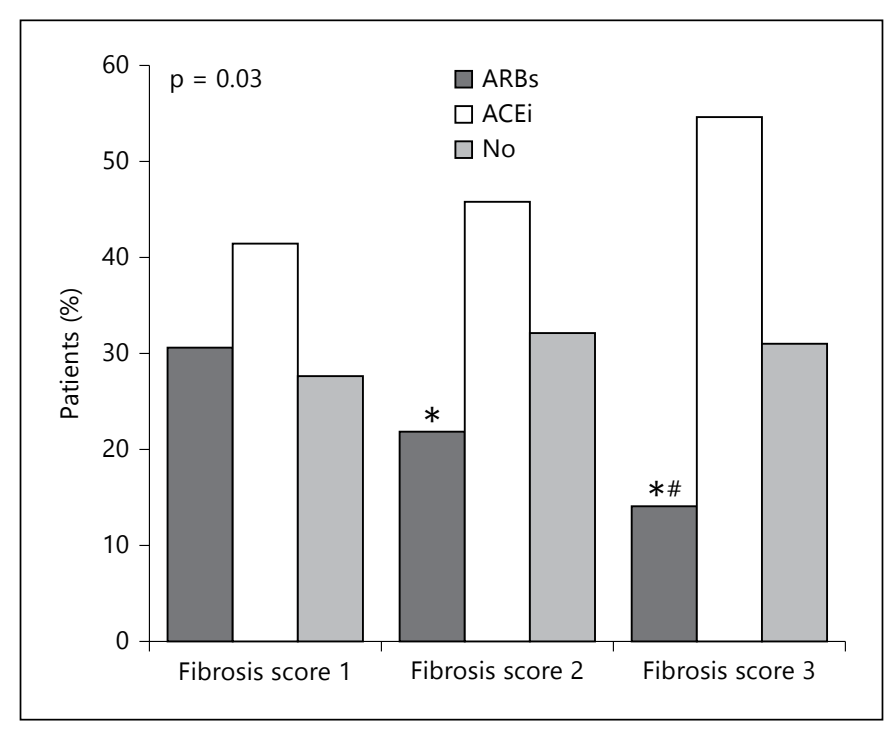

Fig. 3. Percentage of patients under ACEi and ARBs according to the fibrosis score. The percentage of patients under ARBs decreased significantly with the fibrosis score. The use of ACEi was not associated with the fibrosis score. ${ }^{*} \mathrm{p}<0.05$ compared to fibrosis score $1 ;{ }^{\#} \mathrm{p}<0.05$ compared to fibrosis score 2 .

Table 5. Multivariate linear analysis of fibrosis score

\begin{tabular}{lcl}
\hline Variables & $\beta$ coefficient & p value \\
\hline Age & -0.01 & 0.36 \\
Male gender & 0.11 & 0.31 \\
BMI & 0.03 & 0.07 \\
Mean blood pressure & 0.01 & 0.23 \\
BAV & 0.29 & 0.02 \\
Aortic valve weight & 0.26 & 0.01 \\
LDL particle size & 0.01 & 0.6 \\
ARBs & -0.34 & 0.003
\end{tabular}

$\mathrm{r}^{2}$ adjusted $=0.67 ; \mathrm{p}<0.0001$.

\section{ARBs Are Associated with Lower Density of}

Macrophage and IL-6 Expression within CAVD Valves

The examination of CAVD valves revealed that patients under ARBs but not ACEi had a lower density of macrophages $(\mathrm{ARBs}=4 \pm 2.1, \mathrm{ACEi}=10 \pm 2.05$ and no medication $=11.75 \pm 1.78$ cells $/ 400 \times$ field, $\mathrm{p}=0.04$, ANOVA; fig. 4). There was a tendency $(\mathrm{p}=0.08)$ in patients under ARBs to have a lower level of the chemokine MCP-1 $(\mathrm{ARBs}=0.98 \pm 0.10$ vs. no $\mathrm{ARBs}=1.21 \pm$ 0.11 copies/HPRT, $\mathrm{p}=0.08$ ).

The density of macrophages was not associated with the fibrosis score of the aortic valve (score $1=6.1 \pm 3.6$, score $2=10.1 \pm 2.0$ and score $3=14.1 \pm 2.7$ cells $/ 400 \times$

Fibrosis of Aortic Valve and Angiotensin

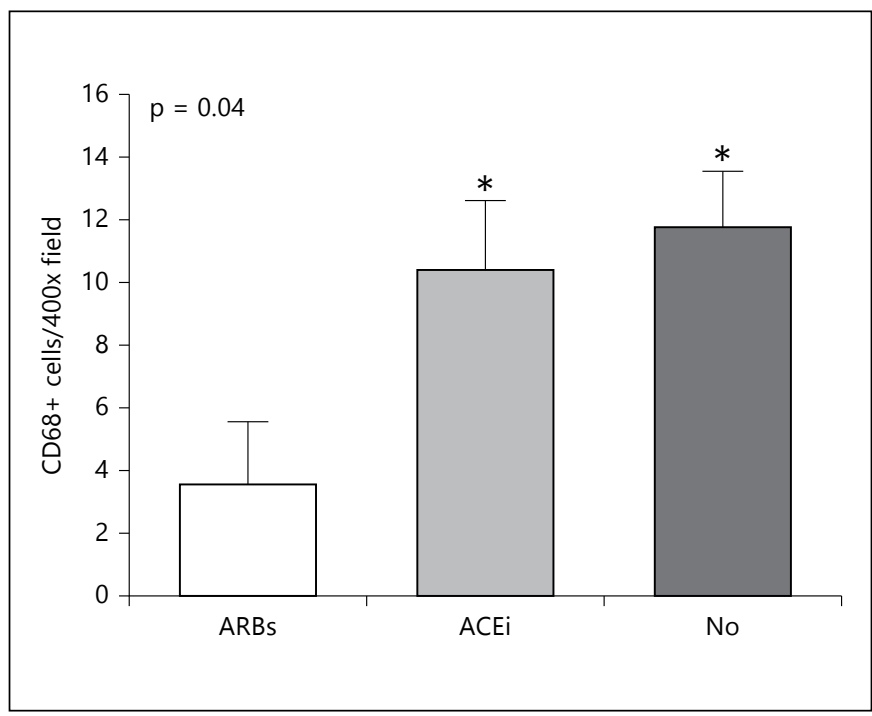

Fig. 4. The use of ARBs but not ACEi was significantly associated with a lower density of macrophages (CD68+ cells) in CAVD tissues. ${ }^{*} \mathrm{p}<0.05$ compared to ARBs.

field, $\mathrm{p}=0.20$, ANOVA), whereas the expression of IL-6, a cytokine highly expressed in CAVD tissues, was significantly associated with fibrosis. In this regard, after measurement of IL- 6 by qPCR, we found that IL- 6 transcript levels increased significantly with the aortic valve fibrosis score $(\mathrm{p}=0.02$; fig. $5 \mathrm{a})$. The level of transcripts encoding for other cytokines such as TNFa $(\mathrm{p}=0.36)$ or IL- $1 \beta(p=0.32)$ were not significantly related to the remodeling score of the aortic valves (data not shown). Of interest, ARBs but not ACEi were associated with reduced levels of IL- 6 transcripts in CAVD (ARBs = $1.74 \pm 0.68, \mathrm{ACEi}=3.24 \pm 0.6$ and no medication $=4.25 \pm$ 0.39 copies/HPRT, $\mathrm{p}=0.03$, ANOVA; fig. $5 \mathrm{~b}$ ).

\section{Discussion}

In this study, we report that the fibrotic component of the aortic valve remodeling process was related to the severity of CAVD. Furthermore, we found that the small, dense LDL phenotype was independently related to the fibrosis of the aortic valve. More importantly perhaps, we also observed that patients under ARBs, despite having more cardiovascular risk factors (with elevated BMI and smaller mean LDL particle size), had a lower fibrosis score of the aortic valve and this even after adjustment for covariates. Hence, this study raises the possibility that 


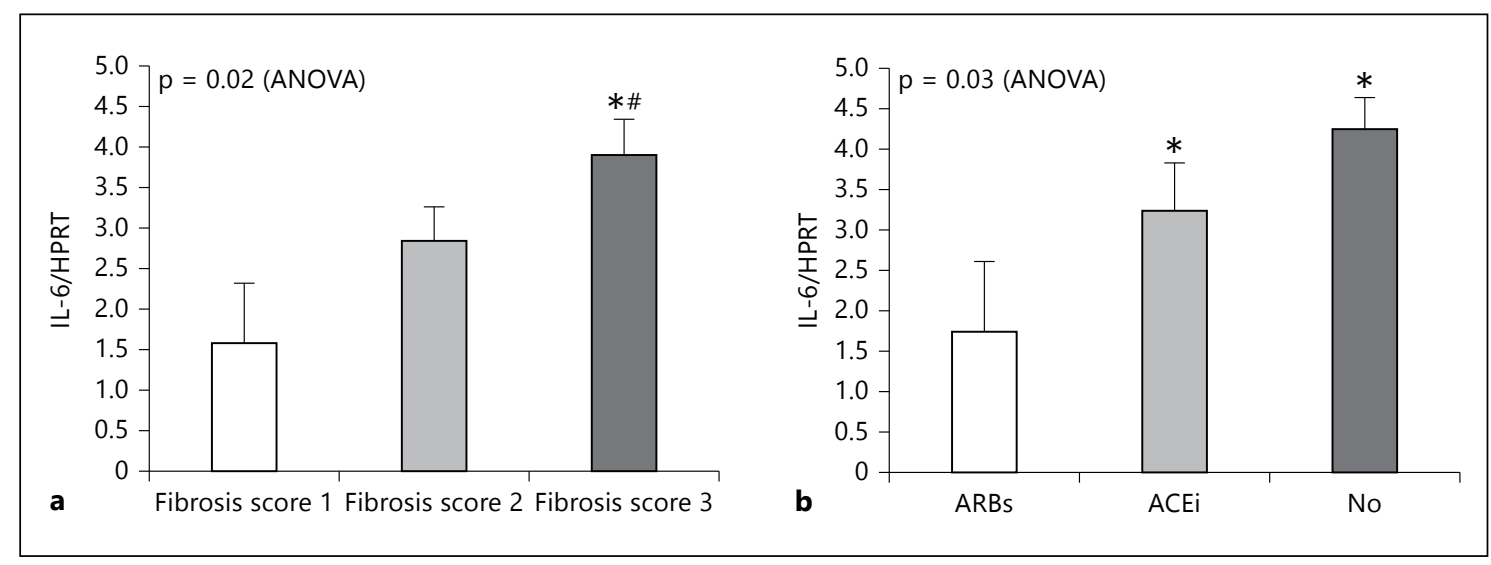

Fig. 5. a Positive relationship between the valve fibrosis score and IL-6 expression (measured by qPCR) in CAVD valves; ${ }^{*} \mathrm{p}<0.05$ compared to fibrosis score 1 ; $^{\#} \mathrm{p}<0.05$ compared to fibrosis score 2 . $\mathbf{b}$ ARBs but not ACEi were related to a decreased IL- 6 expression in CAVD valves. ${ }^{*} \mathrm{p}<0.05$ compared to ARBs.

ARBs might have a potential role in preventing fibrosis of the aortic valve tissue, which is an important component in the pathobiology of CAVD.

\section{Small Dense LDL and CAVD}

We previously reported that small, dense LDLs are associated with aortic valve accumulation of oxidized LDL and valvular inflammation [11]. On this score, it should be pointed out that small, dense LDLs have a higher oxidation rate and may thus promote tissue inflammation [6]. On the one hand, it is worth emphasizing that the small, dense LDL phenotype is closely associated with visceral obesity and the presence of the metabolic syndrome $[4,12]$. On the other hand, the metabolic syndrome has been linked to a higher prevalence of aortic valve calcification as well as to a faster progression of CAVD $[13,14]$. It then follows that metabolic perturbations related to obesity are likely to be major players in the development/progression of CAVD. Among other things, obesity is also well known for its activation of the RAS, which may be one crucial component in the activation of inflammation along with the small, dense LDL phenotype [15]. To this effect, activation of the RAS has been linked to aortic valve inflammation in a group of prehypertensive men with CAVD [16]. Thus, intricate links exist between the RAS, valvular inflammation and the small, dense LDL particles.

\section{Relevance of Fibrosis to the Pathobiology of CAVD}

The present study emphasizes that along with mineralization, fibrosis is an important contributor to the pathobiology of CAVD. In this regard, we documented that the fibrotic component of CAVD is independently relat- ed to hemodynamic indices of severity. Also worthy of note, we found that the level of fibrosis of the aortic valve was associated with the amount of calcium within the aortic valve. Hence, these findings underscore that mineralization of CAVD is intertwined with fibrosis, with both processes playing a mutual role in the pathology. This study is in line with recent findings indicating that the expression of genes related to fibrosis is highly upregulated in CAVD [17]. Therefore, this study also underscores the importance of analyzing the effect of potential novel therapeutic drugs for CAVD on the fibrotic process of the aortic valve.

\section{$A R B s$ and $C A V D$}

The RAS is well known for its activation of inflammation and fibrosis. We previously reported that ARBs were associated with a lower remodeling of the aortic valve in 208 patients with CAVD [18]. In the present study we further refined our previous findings and found in 477 patients that ARBs were independently associated with a lower fibrosis score of the aortic valve, which is one component of the remodeling process along with mineralization. It should be underlined that ARBs were not associated with a lower amount of calcium within CAVD tissue, suggesting that ARBs may act predominantly by altering the fibrotic process of the aortic valve. In the present study, we found that the use of ARBs was associated with a lower accumulation of macrophages and also a reduced number of IL- 6 transcripts within CAVD tissue. Furthermore, we found that the expression of IL- 6 in CAVD was correlated with the fibrosis score. Of interest, a recent investigation found that cross-talks between macrophage and cardiac fibro- 
blast promote fibrosis through the secretion of IL-6 [9]. These findings are in line with another work, which indicates that angiotensin II promotes IL- 6 expression in the kidney, whereby fibrotic gene expression is triggered [10].

\section{$A R B s$ versus ACEi in CAVD}

Retrospective studies with ACEi have provided conflicting results. One study reported that ACEi were associated with lower accumulation of aortic valve calcium, whereas another report could not find an association between the use of ACEi and the hemodynamic progression of CAVD $[19,20]$. In the present study, we found that ARBs but not ACEi were associated with lower aortic valve inflammation and fibrosis. Along with these findings, one experimental study in hypercholesterolemic rabbits documented that olmesartan, an ARB, significantly reduced the accumulation of macrophages within the aortic valve, as well as the expression of $\alpha$-smooth muscle actin, a marker of cell synthetic activity [21]. The question that arises at this stage is why ARBs but not ACEi are related to reduced fibrosis of the aortic valve. The answer may reside in the fact that an angiotensin II-producing enzyme, chymase, is abundantly expressed in CAVD tissue and is not blocked by ACEi [8]. Blocking the RAS downstream of the cascade with ARBs may thus provide a more effective means to control the RAS-mediated effect on the aortic valve, namely the fibrotic process. To this effect, the finding in the present study that the use of ARBs but not ACEi is associated with a lower aortic valve infiltration in macrophages and a lower level of IL-6 transcripts support the latter hypothesis.

\section{Limitations}

Insofar this study has examined CAVD tissue with an advanced pathological process mandating surgery, the present conclusion cannot be necessarily transposed to the early phase of the disease process. A cause-and-effect relationship cannot be ascertained from cross-sectional observations. Also, the duration of the medication is unknown. Nonetheless, the present findings provide evidence that ARBs may have a biological activity in CAVD by decreasing tissue inflammation and fibrosis of the aortic valve. Further experimental and clinical studies evaluating the role of ARBs in the progression of CAVD are thus warranted.

\section{Conclusion}

Fibrosis of the aortic valve is one important component in the pathobiological process leading to the development of CAVD. ARBs are independently related to a lower fibrosis score of CAVD. This effect of ARBs on the fibrosis of the aortic valve could be mediated by the ability of this class of medication to reduce valve inflammation and expression of IL-6, a cytokine possibly related to the fibrotic activity in CAVD.

\section{Acknowledgements}

This work was supported by a HSFC grant (P.M.), CIHR grants MOP114893 (P.M.) and MOP 79342 (P.P.) and the Quebec Heart and Lung Institute Fund (P.M.). N.C. is supported by studentship grants from Fonds de Recherche en Santé du Québec; Y.B. is a research scholar from the Heart and Stroke Foundation of Canada; $\mathrm{P}$. Mathieu is a research scholar from the Fonds de Recherche en Santé du Québec; P.P. holds the Canada Research Chair in Valvular Heart Diseases, and J-P.D. holds the International Chair on Cardiometabolic Risk at Université Laval.

\section{Disclosure Statement}

None.

\section{References}

1 Rajamannan NM, Evans FJ, Aikawa E, GrandeAllen KJ, Demer LL, Heistad DD, Simmons CA, Masters KS, Mathieu P, O'Brien KD, Schoen FJ, Towler DA, Yoganathan AP, Otto CM: Calcific aortic valve disease: not simply a degenerative process. A review and agenda for research from the National Heart and Lung and Blood Institute Aortic Stenosis Working Group. Executive summary: calcific aortic valve disease - 2011 update. Circulation 2011;124: 1783-1791.

2 Stewart BF, Siscovick D, Lind BK, Gardin JM, Gottdiener JS, Smith VE, Kitzman DW, Otto

Fibrosis of Aortic Valve and Angiotensin
CM: Clinical factors associated with calcific aortic valve disease. Cardiovascular Health Study. J Am Coll Cardiol 1997;29:630-634.

-3 Mathieu P, Despres JP, Pibarot P: The 'valvulometabolic' risk in calcific aortic valve disease. Can J Cardiol 2007;23(suppl B):32B-39B.

-4 Mathieu P, Poirier P, Pibarot P, Lemieux I, Despres JP: Visceral obesity: the link among inflammation, hypertension, and cardiovascular disease. Hypertension 2009;53:577-584.

5 Mathieu P, Lemieux I, Despres JP: Obesity, inflammation, and cardiovascular risk. Clin $\mathrm{Ph}-$ armacol Ther 2010;87:407-416.
6 Cote C, Pibarot P, Despres JP, Mohty D, Cartier A, Arsenault BJ, Couture C, Mathieu P: Association between circulating oxidised low-density lipoprotein and fibrocalcific remodelling of the aortic valve in aortic stenosis. Heart 2008;94: 1175-1180.

7 O’Brien KD, Shavelle DM, Caulfield MT, McDonald TO, Olin-Lewis K, Otto CM, Probstfield JL: Association of angiotensinconverting enzyme with low-density lipoprotein in aortic valvular lesions and in human plasma. Circulation 2002;106:22242230 . 
8 Helske S, Lindstedt KA, Laine M, Mayranpaa M, Werkkala K, Lommi J, Turto H, Kupari M, Kovanen PT: Induction of local angiotensin II-producing systems in stenotic aortic valves. J Am Coll Cardiol 2004;44:1859-1866.

$\checkmark 9$ Ma F, Li Y, Jia L, Han Y, Cheng J, Li H, Qi Y, Du J: Macrophage-stimulated cardiac fibroblast production of IL-6 is essential for TGF $\beta /$ Smad activation and cardiac fibrosis induced by angiotensin II. PLoS One 2012; 7:e35144.

10 Zhang W, Wang W, Yu H, Zhang Y, Dai Y, Ning C, Tao L, Sun H, Kellems RE, Blackburn MR, Xia Y: Interleukin 6 underlies angiotensin II-induced hypertension and chronic renal damage. Hypertension 2012;59: 136-144.

11 Mohty D, Pibarot P, Despres JP, Cote C, Arsenault B, Cartier A, Cosnay P, Couture C, Mathieu P: Association between plasma LDL particle size, valvular accumulation of oxidized LDL, and inflammation in patients with aortic stenosis. Arterioscler Thromb Vasc Biol 2008;28:187-193.

12 Mathieu P, Pibarot P, Larose E, Poirier P, Marette A, Despres JP: Visceral obesity and the heart. Int J Biochem Cell Biol 2008;40:821836
13 Briand M, Lemieux I, Dumesnil JG, Mathieu P, Cartier A, Despres JP, Arsenault M, Couet J, Pibarot P: Metabolic syndrome negatively influences disease progression and prognosis in aortic stenosis. J Am Coll Cardiol 2006;47: 2229-2236.

14 Katz R, Wong ND, Kronmal R, Takasu J, Shavelle DM, Probstfield JL, Bertoni AG, Budoff MJ, O'Brien KD: Features of the metabolic syndrome and diabetes mellitus as predictors of aortic valve calcification in the Multi-Ethnic Study of Atherosclerosis. Circulation 2006;113: 2113-2119.

15 Despres JP, Lemieux I, Bergeron J, Pibarot P, Mathieu P, Larose E, Rodes-Cabau J, Bertrand OF, Poirier P: Abdominal obesity and the metabolic syndrome: contribution to global cardiometabolic risk. Arterioscler Thromb Vasc Biol 2008;28:1039-1049.

16 Cote N, Pibarot P, Pepin A, Fournier D, Audet A, Arsenault B, Couture C, Poirier P, Despres JP, Mathieu P: Oxidized low-density lipoprotein, angiotensin II and increased waist circumference are associated with valve inflammation in prehypertensive patients with aortic stenosis. Int J Cardiol 2010;145:444-449.
17 Bosse Y, Miqdad A, Fournier D, Pepin A, Pibarot P, Mathieu P: Refining molecular pathways leading to calcific aortic valve stenosis by studying gene expression profile of normal and calcified stenotic human aortic valves. Circ Cardiovasc Genet 2009;2:489-498.

18 Cote N, Couture C, Pibarot P, Despres JP, Mathieu P: Angiotensin receptor blockers are associated with a lower remodelling score of stenotic aortic valves. Eur J Clin Invest 2011;41: 1172-1179.

19 O’Brien KD, Probstfield JL, Caulfield MT, Nasir K, Takasu J, Shavelle DM, Wu AH, Zhao XQ, Budoff MJ: Angiotensin-converting enzyme inhibitors and change in aortic valve calcium. Arch Intern Med 2005;165:858-862.

20 Rosenhek R, Rader F, Loho N, Gabriel H, Heger M, Klaar U, Schemper M, Binder T, Maurer G, Baumgartner H: Statins but not angiotensin-converting enzyme inhibitors delay progression of aortic stenosis. Circulation 2004;110:1291-1295.

21 Arishiro K, Hoshiga M, Negoro N, Jin D, Takai S, Miyazaki M, Ishihara T, Hanafusa T: Angiotensin receptor-1 blocker inhibits atherosclerotic changes and endothelial disruption of the aortic valve in hypercholesterolemic rabbits. J Am Coll Cardiol 2007;49:1482-1489. 